\title{
Prospective, randomized comparison of intravenous and oral ciprofloxacin with intravenous ceftazidime in the treatment of nosocomial pneumonia
}

\begin{abstract}
Raphael SaGinur mD frCPC, Gary Garber mD frCPC, Gail Darling mD frCsC, StePHen SHAFran mD frCPC, WILLIAM CAMERON MD FRCPC, GWYNNE JONES MD FRCP (UK) FRCPC, FRANCOIS AUCLAIR MD FRCPC, and the Canadian Infectious Disease Society Multicenter Nosocomial Pneumonia Study Group
\end{abstract}

\footnotetext{
R SAGINUR, G GARBER, G DARLING, et al. Prospective, randomized comparison of intravenous and oral ciprofloxacin with intravenous ceftazidime in the treatment of nosocomial pneumonia. Can J Infect Dis 1997;8(2):89-94.
}

\begin{abstract}
OBJECTIVE: To compare the efficacy of intravenous and oral ciprofloxacin and intravenous ceftazidime in the treatment of nosocomial pneumonia.

DESIGN: Randomized, nonblinded, multicentre comparative trial.

SETTING: Seven Canadian university hospitals.

POPULATION: Adult patients with moderate to severe pneumonia developing $72 \mathrm{~h}$ or longer after hospitalization. METHODS: After informed consent was obtained, patients were randomized to receive intravenous ciprofloxacin 300 mg every $12 \mathrm{~h}$ or ceftazidime $2 \mathrm{~g}$ every $8 \mathrm{~h}$. After three days, patients in the ciprofloxacin arm could be switched to oral ciprofloxacin, $750 \mathrm{mg}$ every $12 \mathrm{~h}$. Concomitant clindamycin was allowed for three days in patients with syndromes consistent with Gram-positive or anaerobic infection. Erythromycin could be used if cultures revealed no pathogen. RESULTS: A total of 149 patients were enrolled, of whom 124 were eligible for efficacy analysis. Of 119 pathogens identified in 87 patients, 84 were Gram-negative, and 35 Gram-positive. The mean duration of ciprofloxacin therapy was 12.1 days, of which 9.2 days were given intravenously. Ceftazidime was given for a mean of 9.8 days. There was eradication or reduction of pathogens in $75.7 \%$ of ciprofloxacin patients and $70.6 \%$ of the ceftazidime group. Clinical resolution or improvement occurred in $87.1 \%$ of ciprofloxacin recipients and $87.3 \%$ of the ceftazidime group. Eight ciprofloxacin and six ceftazidime patients died. Overall outcomes were considered to be successful in $85.2 \%$ of ciprofloxacin patients and $87.1 \%$ of ceftazidime recipients. Adverse events were mild.

CONCLUSIONS: There were similar efficacy and safety of intravenous and oral ciprofloxacin and intravenous ceftazidime in the treatment of patients with hospital-acquired pneumonia. Physicians were reluctant to use oral therapy in patients.
\end{abstract}

Key Words: Cephalosporins, Fluoroquinolones, Nosocomial infection, Pneumonia

Department of Medicine, Ottawa Civic Hospital; Department of Medicine, Ottawa General Hospital; University of Ottawa, Ottawa, Ontario; Department of Surgery, Wellesley Hospital and University of Toronto, Toronto, Ontario; Department of Medicine, University of Alberta Hospitals; University of Alberta, Edmonton, Alberta

Correspondence and reprints: Dr R Saginur, Division of Infectious Diseases, Department of Medicine, Ottawa Civic Hospital, 1053 Carling Avenue, Ottawa, Ontario K1Y 4E9. Telephone 613-761-4155, fax 613-761-5340, e-mail rsaginur@civich.ottawa.on.ca

Received for publication January 12, 1996. Accepted September 2, 1996 


\title{
Comparaison prospective randomisée de la ciprofloxacine intraveineuse et orale et de la ceftazidime intraveineuse dans le traitement de la pneumonie nosocomiale
}

\begin{abstract}
OBJECTIF : Comparer l'efficacité de la ciprofloxacine intraveineuse et orale et de la ceftazidime intraveineuse contre la pneumonie nosocomiale.

MODÈLE : Essai comparatif randomisé au su, multicentrique.

CONTEXTE : Sept hôpitaux universitaires canadiens.

POPULATION : Patients adultes, atteints de pneumonie de modérée à grave, s'étant installée dans les 72 heures ou plus après l'hospitalisation.

INTERACTIONS : Après l'obtention d'un consentement éclairé, les patients ont été randomisés en vue de recevoir de la ciprofloxacine intraveineuse $300 \mathrm{mg}$ toutes les 12 heures ou de la ceftazidime $2 \mathrm{~g}$ toutes les huit heures. Après trois jours, les patients du groupe ciprofloxacine pouvaient passer à la ciprofloxacine orale, à raison de $750 \mathrm{mg}$ toutes les 12 heures. L'administration concomitante de clindamycine a été permise pendant trois jours chez les patients présentant des syndromes concordant avec une infection gram-positive ou anaérobie. L'érythromycine pouvait être utilisée si les cultures révélaient l'absence de pathogène.

RÉSULTATS : En tout, 149 patients ont été inscrits, dont 124 ont été jugés admissibles pour l'analyse d'efficacité. Parmi les 119 organismes pathogènes identifiés chez 87 patients, 84 étaient gram-négatifs et 35 gram-positifs. La durée moyenne du traitement par ciprofloxacine a été de 12,1 jours, dont 9,2 de traitement intraveineux. La ceftazidime a été administrée en moyenne 9,8 jours. On a noté une éradication et une réduction des organismes pathogènes chez 75,7 \% des patients sous ciprofloxacine et $70,6 \%$ des patients sous ceftazidime. La résolution clinique et l'amélioration ont été notées chez $87,1 \%$ des patients sous ciprofloxacine et $87,3 \%$ des patients sous ceftazidime. Huit patients sous ciprofloxacine et six patients sous ceftazidime sont décédés. Les résultats globaux ont été jugés favorables chez $85,2 \%$ des patients sous ciprofloxacine et chez $87,1 \%$ des patients sous ceftazidime. Les réactions indésirables ont été bénignes. CONCLUSIONS : On observe une efficacité et une innocuité similaires entre la ciprofloxacine intraveineuse et orale et la ceftazidime intraveineuse pour le traitement des patients atteints de pneumonie nosocomiale. Les médecins ont été réticents à employer le traitement oral chez les patients.
\end{abstract}

$\mathrm{T}$ he impact of nosocomial infections, in terms of attributable morbidity, mortality and cost, is enormous. Nosocomial infection rates are increasing in the United States and Canada. This relates in part to the increased number of debilitated patients who live with chronic disease. The use of invasive monitoring and therapeutic measures augments the problem (1).

Nosocomial pneumonia affects over 250,000 acute care patients annually in the United States (2), with critically ill and intubated patients incurring a particularly high risk $(3,4)$. In a major study of intubated patients in which nosocomial pneumonia was diagnosed by clinical criteria and confirmed by protected bronchoscopy or bronchoalveolar lavage, the mortality in patients with pneumonia was $54 \%$ compared with $27 \%$ for controls matched for underlying disease (5). The length of stay was prolonged by 13 days on average.

Hospital-acquired pneumonia can substantially increase the cost of hospitalization by increasing duration of mechanical ventilation, time in the intensive care unit and overall hospital stay. The direct cost of diagnosing and treating nosocomial pneumonia in the United States exceeds one billion US dollars per year (4-6). There are no comparable Canadian data.

The diagnosis of nosocomial pneumonia is usually made on clinical grounds, in the absence of a specific diagnostic test. Because of the uncertainty of diagnosis in the individual case, the apparent etiological agent found on cultures of respiratory secretions may reflect colonization rather than true infection. The common causes of nosocomial pneumonia in patients hospitalized for more than three days are aerobic Gram-negative bacilli such as Klebsiella pneumoniae, Enterobacter species, Serratia species or Pseudomonas aeruginosa as well as
Staphylococcus aureus $(7,8)$. Multiple bacterial organisms are often the cause, with viral and fungal infection found much less frequently (4). In a Canadian series, $S$ aureus, Streptococcus pneumoniae and Haemophilus influenzae were found to be important pathogens (9).

Ciprofloxacin is a fluoroquinolone antibiotic with activity against a wide range of Gram-negative and Gram-positive organisms. It has been shown to penetrate lung tissue and rapidly kills respiratory pathogens (10). It is well absorbed when given orally. Intravenous ciprofloxacin has been shown to be highly effective in the treatment of severe pneumonia (11). These properties of ciprofloxacin suggest that the possibility of sequential therapy, intravenous followed by oral, has the potential to provide substantial cost savings, through reduced drug acquisition costs and reduced duration of hospitalization.

Ceftazidime, a third-generation cephalosporin with a high degree of activity against aerobic and facultative Gram-negative rods, has been shown to be effective therapy for nosocomial pneumonia (12).

The objective of this study was to compare the efficacy and safety of intravenous and oral ciprofloxacin with intravenous ceftazidime in the treatment of moderate to severe pneumonia in hospitalized patients.

\section{PATIENTS AND METHODS}

This was a multicentre, prospective, randomized, parallel, nonblinded clinical trial conducted at seven Canadian medical centres. The protocol was approved by the Human Experimentation Committee of each centre, and informed consent was obtained from each patient (or designate) before enrolment. 
For the purposes of this trial, hospital-acquired pneumonia was defined as occurring more than $72 \mathrm{~h}$ after admission.

Inclusion criteria were patient age 18 years or older; moderate or severe pneumonia developing after $72 \mathrm{~h}$ in hospital; infiltrate on chest x-ray; and clinical symptoms and signs, including new onset of cough with sputum production with or without leucocytosis, presence of fever $38^{\circ} \mathrm{C}$ or higher, and reliable sputum specimens for culture (more than 25 polymorphonuclear leucocytes/high power field; fewer than 10 squamous epithelial cells/high power field) obtained by deep cough, endotracheal suction or protected brush bronchoscopy.

Exclusion criteria were patients at high risk of death within $72 \mathrm{~h}$ of study enrolment; a history of allergy or severe adverse reaction to ciprofloxacin, other quinolone derivatives or cephalosporins; pregnancy or lactation; severe renal impairment (serum creatinine more than $265 \mu \mathrm{mol} / \mathrm{L}$ ); mild infection not requiring parenteral antibiotics; alternative diagnosis for pulmonary infiltrate (eg, cardiac failure, pulmonary embolus, etc); prior oral or parenteral antibiotics for this infection with the exception of cases of clinical worsening after a course of less than $48 \mathrm{~h}$; concomitant antibiotics for other infection where the antibiotics have a similar spectrum of activity; previous enrolment in this study; or granulocytopenia or known human immunodeficiency virus infection.

Patients were assigned by a randomization code established for each participating centre. After enrolment and consent was obtained, the pharmacist dispensed the appropriate drugs. There were two randomization lists - one for intubated and ventilated patients and a second list for nonventilated patients.

Patients received either ciprofloxacin $300 \mathrm{mg}$ intravenously every $12 \mathrm{~h}$ or ceftazidime $2 \mathrm{~g}$ every $8 \mathrm{~h}$. In the ciprofloxacin arm, intravenous dosing was continued for a minimum of $72 \mathrm{~h}$. Thereafter patients were considered for step down to oral therapy, if their condition allowed it and if they were able to ingest and absorb oral ciprofloxacin.

The dose of oral ciprofloxacin was $750 \mathrm{mg}$ every $12 \mathrm{~h}$. The ceftazidime group received only intravenous therapy.

In all arms, clindamycin $600 \mathrm{mg}$ intravenous evey $6 \mathrm{~h}$ could be added as initial concomitant therapy. At 96 h, if pneumococcus or anaerobic bacteria were not suspected as pathogens, clindamycin was discontinued. If no pathogen was identified, the investigator could choose to initiate erythromycin 500 to $1000 \mathrm{mg}$ every $6 \mathrm{~h}$ intravenous instead of clindamycin, with acute and convalescent serological studies performed. If the patient failed to respond to therapy after $96 \mathrm{~h}$, the patient was classified as a treatment failure and treated with appropriate antibiotics. Patients were evaluated for clinical and bacteriological response.

Clinical evaluation: Patients were eligible for safety evaluation after having received any study drug. The drugs were evaluated for efficacy after $96 \mathrm{~h}$, unless there was clear evidence of failure within that time.

Clinical efficacy was defined as complete resolution, failure or indeterminate response. Complete resolution was defined as the disappearance of all clinical signs and symptoms related to the infection. Improvement was defined as a marked or moderate reduction in the severity of signs and symptoms of infection. Either complete resolution or improvement were considered a clinical response. Failure was defined as insufficient decrease in signs and symptoms of infection. Indeterminate was defined as no evaluation possible for any reason. Patients who died due to an underlying disease where before death there was evidence of improvement in the infection were considered as an improvement. If the infection had not improved before death or the infection was judged to contribute to the patient's demise, the response was graded a failure.

The bacteriological response was based on the results of appropriate cultures and Gram stain of specimens taken before, during and after therapy. Eradication was defined as causative organism(s) absent at the end of therapy. Reduction was considered a greater than 2 log reduction in organism to a clinically insignificant level. Eradication with relapse was defined as causative organism(s) absent at end of therapy but that reappeared on or before a follow-up visit. Eradication with reinfection was the absence of causative organisms at end of therapy and another infecting organism(s) at or before follow-up visit. Persistence was defined as an organism still present at end of treatment with no significant reduction in number. Superinfection was defined as the presence of a new organism during or at the end of therapy judged to be causing an infectious process. Indeterminate was defined as none of the above.

A combined assessment of antibacterial therapy was made by the investigator at the site, based on clinical and bacteriologic response and defined as completely successful, partially successful, unsuccessful or indeterminate.

Patients were monitored for safety by daily clinical evaluation and with regular blood tests (complete blood counts, glucose, creatinine, urea, uric acid, asparate aminotransferase, alanine aminotransferase, alkaline phosphatase, bilirubin, total protein and albumin, electrolytes), urinalysis and chest x-ray. These were performed at the start of study, every three days during the study, at the end of treatment and at the follow-up visit. Side effects were monitored and graded as mild, moderate or severe. The association of the study $\operatorname{drug}(\mathrm{s})$ with the adverse effect was judged by the clinical investigator as probable, possible, remote or none.

Statistical analysis: Sample size was calculated based on a hypothesis test for the equality of proportions of 'cures' by investigator assessment at the end of therapy. A two-tailed test was used. With alpha $=0.05$, a power of $80 \%$, assuming a ciprofloxacin cure rate of $80 \%$, and a ceftazidime cure rate of $60 \%$, a sample size of 182 patients (91 per arm) was required.

\section{RESULTS}

A total of 149 patients were enrolled in the study. Enrolment was stopped after interim analyses revealed no difference between groups, such that fulfilling the intended patient accrual would not result in significant differences. Demographics of the study population are listed in Table 1. There were no significant differences between the two study groups in terms of age, sex or ventilator status. Twenty-five patients were excluded from the efficacy analysis (Table 2). Reasons for 
TABLE 1

Demographics of study patients

\begin{tabular}{|c|c|c|c|}
\hline & \multicolumn{2}{|c|}{ Treatment group } & \multirow{2}{*}{$\begin{array}{c}\text { Total } \\
(n=149)\end{array}$} \\
\hline & Ceftazidime $(n=77)$ & Ciprofloxacin $(n=72)$ & \\
\hline Age (years) (mean $\pm \mathrm{SE})$ & $62.26 \pm 1.97$ & $60.94 \pm 2.12$ & $61.62 \pm 1.44$ \\
\hline \multicolumn{4}{|l|}{ Sex } \\
\hline Male & 31 (40.26\%) & $25(34.72 \%)$ & $56(35.48 \%)$ \\
\hline Female & $46(59.74 \%)$ & $47(65.28 \%)$ & $93(64.52 \%)$ \\
\hline $\begin{array}{l}\text { Ventilator- } \\
\text { dependent }\end{array}$ & 39 (50.65\%) & $38(52.78 \%)$ & 77 (51.68\%) \\
\hline $\begin{array}{l}\text { Ventilator- } \\
\text { independent }\end{array}$ & $38(49.35 \%)$ & $34(47.22 \%)$ & $72(48.32 \%)$ \\
\hline
\end{tabular}

TABLE 2

Reasons for exclusion from efficacy analysis

\begin{tabular}{lccc}
\hline & \multicolumn{2}{c}{ Treatment group } \\
& Ceftazidime $(\mathbf{n = 9})$ & Ciprofloxacin $(\mathbf{n = 1 6})$ & \multicolumn{1}{c}{ Total $(\mathbf{n}=\mathbf{2 5})$} \\
\hline Unacceptable concomitant medication & 3 & 5 & 9 \\
Duration of therapy too short & 1 & 1 & 6 \\
Incorrect diagnosis & 3 & 1 & 4 \\
Patient withdrawn from study & 0 & 3 & 5 \\
Pneumonia diagnosed less than two days after admission & 2 & 1 \\
\hline
\end{tabular}

invalidity included unacceptable concomitant medications, nine; incorrect diagnosis of pneumonia, four; patient withdrawal from the study, one ( $S$ aureus bacteremia for which cloxacillin was ordered); diagnosis of pneumonia within two days of admission, five; and insufficient duration of therapy, six - one had an untoward reaction to a study drug, two exhibited clinical worsening with development of septic shock or suspected meningitis within $96 \mathrm{~h}$, one had Gram-positive bacteremia, one was considered ineligible for participation and one was discontinued at the discretion of the physician).

Sputum cultures revealed 119 putative pathogens in 87 patients. There were 84 Gram-negative isolates and 35 Grampositive (Table 3).

$S$ pneumoniae and $H$ influenzae pneumonias arose a mean of 7.1 days after admission, compared with 12.3 days for other pathogens $(\mathrm{P}<0.01)$.

The mean duration of ciprofloxacin therapy was 12.1 days (9.2 days intravenous plus 2.9 oral) and the duration of ceftazidime therapy was 9.8 days. There was no difference in the duration of intravenous antibiotics. Thirty-nine evaluable patients in each group received clindamycin, for a mean duration of 9.8 days in the ciprofloxacin arm, and 8.2 days in the ceftazidime arm. Two ceftazidime recipients received concomitant erythromycin.

Bacteriological results were similar with both antibiotics (Table 4). There was eradication or reduction of pathogens at the end of therapy in $75.7 \%$ of ciprofloxacin patients and $70.6 \%$ of ceftazidime recipients. After two to four weeks of follow-up, three ciprofloxacin patients were reinfected compared with four ceftazidime patients. There were no diagnosed relapses with ciprofloxacin, but one with ceftazidime. Among ventilated patients, there was a trend towards greater eradication of pathogens in patients receiving ciprofloxacin compared
TABLE 3

Sputum pathogens isolated, evaluable patients

\begin{tabular}{lcc} 
Gram-negative & & \\
Haemophilus influenzae & 11 & 11 \\
Haemophilus species (other) & 2 & 0 \\
Moraxella catarrhalis & 6 & 2 \\
Klebsiella species & 7 & 4 \\
Enterobacter species & 8 & $3(1)$ \\
Escherichia coli & 1 & 6 \\
Pseudomonas aeruginosa & $2(1)$ & 2 \\
Other Gram-negative rods & 9 & 8 \\
Neisseria species & 1 & 1 \\
Gram-positive & & \\
Staphylococcus aureus & $9(1)$ & $9^{\dagger}$ \\
Streptococcus pneumoniae & 7 & 2 \\
Streptococcus species (other) & 1 & 7 \\
Total & 64 & 55 \\
\hline
\end{tabular}

*One patient with mixed culture from sputum had Enterococcus faecalis bacteremia; ${ }^{\dagger}$ One patient had a concomitant E faecium bacteremia; 0 Indicates number of patients bacteremic

with ceftazidime ( $73 \%$ versus $58 \%$ ). None of these differences is statistically significant.

There was clinical resolution or improvement in $87.1 \%$ of ciprofloxacin recipients, and $87.3 \%$ of the ceftazidime group (Table 5). There were eight deaths in the ciprofloxacin arm, and six in the ceftazidime group.

Overall, investigator assessment of outcome of therapy was success in 46 of 54 ciprofloxacin patients (85.2\%) and 54 of 62 ceftazidime patients (87.1\%).

Adverse events were mild in both groups. Four ciproflox- 
TABLE 4

Bacterological response: End of therapy

\begin{tabular}{|c|c|c|c|c|c|c|}
\hline & \multicolumn{2}{|c|}{ Ciprofloxacin } & \multicolumn{4}{|c|}{ Ceftazidime } \\
\hline & $\begin{array}{l}\text { Ventilator- } \\
\text { dependent }\end{array}$ & $\begin{array}{c}\text { Ventilator- } \\
\text { independent }\end{array}$ & Total & $\begin{array}{l}\text { Ventilator- } \\
\text { dependent }\end{array}$ & $\begin{array}{c}\text { Ventilator- } \\
\text { independent }\end{array}$ & Total \\
\hline Number & 30 & 26 & 56 & 34 & 34 & 68 \\
\hline Eradication (\%) & $19(73.1)$ & $9(81.8)$ & $28(75.7)$ & $14(58.3)$ & $8(80)$ & $22(64.7)$ \\
\hline Reduction (\%) & 0 & 0 & 0 & $1(4.2)$ & $1(10)$ & $2(5.9)$ \\
\hline Persistence (\%) & 0 & 0 & 0 & $1(4.2)$ & 0 & $1(2.9)$ \\
\hline Eradication superinfection (\%) & $2(7.7)$ & 0 & $2(5.4)$ & $3(12.5)$ & $1(10)$ & $4(11.8)$ \\
\hline
\end{tabular}

TABLE 5

Clinical response: End of therapy

\begin{tabular}{lcccccc}
\hline & \multicolumn{2}{c}{ Ciprofloxacin } & \multicolumn{3}{c}{ Ceftazidime } \\
& $\begin{array}{c}\text { Ventilator- } \\
\text { dependent }\end{array}$ & $\begin{array}{c}\text { Ventilator- } \\
\text { independent }\end{array}$ & Total & $\begin{array}{c}\text { Ventilator- } \\
\text { dependent }\end{array}$ & $\begin{array}{c}\text { Ventilator- } \\
\text { independent }\end{array}$ & Total \\
\hline Resolution (\%) & $17(56.7)$ & $17(70.8)$ & $34(63.0)$ & $14(46.7)$ & $23(69.7)$ & $37(58.7)$ \\
Improvement (\%) & $9(26.7)$ & $5(20.8)$ & $13(24.1)$ & $11(36.7)$ & $7(21.2)$ & $18(28.6)$ \\
Failure (\%) & $3(10)$ & $1(4.2)$ & $4(7.4)$ & $3(10)$ & $2(6.1)$ & $5(7.8)$ \\
Indeterminate (\%) & $2(6.7)$ & $1(4.2)$ & $3(5.6)$ & $2(6.7)$ & $1(3.0)$ & $3(4.8)$ \\
Missing & 0 & 2 & 2 & 4 & 5 & 1 \\
\hline
\end{tabular}

acin recipients developed rashes, and three developed diarrhea. Two ceftazidime patients experienced rashes, one had diarrhea, and one developed renal insufficiency. Only rash and diarrhea were attributed to the antibiotics by the investigator assessing the patient.

\section{DISCUSSION}

In this study, intravenous followed by oral ciprofloxacin was clinically equivalent to intravenous ceftazidime for the treatment of moderately severe nosocomial pneumonia. Mortality was similar in both groups. There was a trend towards greater eradication of pathogens with ciprofloxacin compared with ceftazidime, particularly in ventilated patients.

Clindamycin was used concomitantly with the study drugs in the majority of patients. As a result, no conclusions can be drawn about relative efficacies of ciprofloxacin and ceftazidime against Gram-positive pathogens.

This study extends the observations of Schentag et al (10) who noted more rapid clearance of pathogens causing nosocomial pneumonia in patients receiving ciprofloxacin compared with cephalosporins. The apparently greater bacteriological efficacy was not reflected in greater clinical efficacy.

The option of stepping down to oral therapy was performed in an attempt to shorten the duration of intravenous therapy, reducing cost directly (antibiotics, drug administration) and indirectly, permitting a reduced duration of intensive care unit and/or hospital stays. Physicians were reluctant to switch patients in the ciprofloxacin group from intravenous to oral therapy. Duration of intravenous treatment in the two groups was similar. The ciprofloxacin group was continued on oral therapy. There is no evidence of a lesser response to ciprofloxacin nor of delay in response. From our data, we cannot assess whether the oral ciprofloxacin was necessary. It is possible that the patients in the ciprofloxacin arm would have fared as well without the additional oral therapy.

This finding is similar to those of Khan and Basir (13). In that study, the duration of ceftazidime used in the therapy of lower respiratory tract infection, community- and hospital-acquired, was seven days; the duration of ciprofloxacin was six days intravenous plus five days oral. There was equal efficacy in both study arms, similar to our results.

In a smaller study, duration of ciprofloxacin was 11.7 days (6.2 days intravenous plus 5.5 days oral) compared with 6.9 days intravenous ceftazidime, plus oral therapy of unknown duration in eight of 21 patients for hospital- or nursing homeacquired lower respiratory tract infection, 41 of 47 being pneumonia (14). Ciprofloxacin was significantly more effective than ceftazidime $(\mathrm{P}<0.025)$, with 23 of 23 responding versus 15 of 21 , despite the low dose of ciprofloxacin, $200 \mathrm{mg}$ every $12 \mathrm{~h}$. The ceftazidime group was sicker, with a mean APACHE II score of 19.7 versus 16.0 in the ciprofloxacin arm $(\mathrm{P}<0.025)$. Fink et al (11) compared intravenous ciprofloxacin with imipenem in a population of patients with severe pneumonia, both community- and hospital-acquired (11). There were similar clinical outcomes in both arms, with $20 \%$ mortality in each. In that study there was a trend towards greater bacteriological efficacy of ciprofloxacin.

Patients with nosocomial pneumonia tend to be a severely 
ill group of people, many of whom with comorbidity affecting the suitability of an oral quinolone. Paralytic ileus from abdominal or metabolic pathology can make oral therapy impossible in a certain proportion of patients. Mechanical ventilation or the use of certain antacid or cytoprotective medications for the prevention of peptic ulcer disease, which impair quinolone absorption, makes oral therapy inconvenient or ineffective (15).

Alternatively, physicians may be reluctant to use oral therapy in patients with severe pneumonia or any pneumonia complicating severe underlying illness. There was, until the advent of fluoroquinolones, limited availability of oral therapy against Gram-negative pathogens that predominate in nosocomial pneumonia. Thus, there has been limited clinical experience with oral therapy in this disease.

There is concern about the reliability and the degree of absorption of oral medication because of the patient's comorbidity or concomitant therapy. With a severely ill patient, the physician often requires a greater assurance of efficacy of therapy and is unwilling to risk using step down or second-line therapy, with the potential of sacrificing a gravely ill patient for a modest economic gain. Established clinical practice has accustomed physicians to intravenous therapy for all such patients, even when there is equal bioavailability with oral administration.

At the inception of the study, intravenous ciprofloxacin was not available in Canada, and an economic analysis was not designed prospectively. Using data from this protocol and prices of ciprofloxacin and ceftazidime in Canada, a lesser cost for ciprofloxacin has been demonstrated (personal communi-

\section{REFERENCES}

1. Wenzel RP, ed. Prevention and Control of Nosocomial Infections, 2nd edn. Baltimore: Williams and Wilkins, 1993:v.

2. Wenzel RP. Hospital acquired pneumonia overview of the current state of the art for prevention and control. Eur J Clin Microbiol Infect Dis 1989;8:56-60.

3. Torres A, Aznor R, Gatell JM, et al. Incidence, risk and prognosis factors of nosocomial pneumonia in mechanically ventilated patients. Am Rev Resp Dis 1990;142:523-8.

4. Craven DE, Steger KA, Duncan RA. Prevention and control of nosocomial pneumonia. In: Wenzel RP, ed. Prevention and Control of Nosocomial Infection, 2nd edn. Baltimore: Williams and Wilkins, 1993:580-99.

5. Fagon JY, Chastre J, Hance AJ, Montravers P, Novara A, Gibert C. Nosocomial pneumonia in ventilated patients. A cohort study evaluating attributable mortality and hospital stay. Am J Med 1993;94:281-7.

6. Leu HS, Kaiser DL, Mori M, Woolson RF, Wenzel RP. Hospital acquired pneumonia; attributable mortality and morbidity. Am J Epidemiol 1989;129:1258-67.

7. Berk SL, Verghese A. Emerging pathogens in nosocomial pneumonia. Eur J Clin Microbiol Infect Dis 1989;8:11-4.

8. Pugin J, Auckenthalen R, Mili N, Janssens JP, Lew PD, Suter PM. Diagnosis of ventilator-associated pneumonia by bacteriologic analysis of bronchoscopic and non-bronchoscopic 'blind' bronchoalveolar lavage fluid. Am Rev Respir Dis 1991;143:1121-9. cation). The difference in cost reflected the greater acquisition cost of $6 \mathrm{~g}$ per day of ceftazidime compared with intravenous ciprofloxacin. This cost advantage would be eliminated if the calculations used a dose of ceftazidime of $3 \mathrm{~g}$ per day which is commonly employed.

Pharmacokinetic and pharmacodynamic data and burgeoning clinical experience suggest that it might be reasonable to adopt oral therapy for a significant proportion of patients who traditionally receive intravenous antibiotics. The high bioavailability of fluoroquinolones accelerates the process of rethinking our habits. Economic necessity further forces us to scrutinize our practice of intravenous, hospital-based therapies.

Oral therapy, when suitable, is better tolerated than intravenous. It spares the patient the necessity of an intravenous catheter and in a certain proportion of patients allows discharge home. The risk of intravenous phlebitis or line sepsis is obviated. It economizes on the cost of drug and supplies of any administration and, perhaps, on hospitalization. All physicians treating severe or moderately severe infections normally necessitating intravenous antibiotics must consider the use of oral therapy instead of intravenous treatment, or as step down from it. Since the completion of this study, step down therapy has been approved by the Health Protection Branch and is being widely adopted into clinical practice.

ACKNOWLEDGEMENT: This study was done under the auspices of the Clinical Trials Committee of the Canadian Infectious Diseases Society, with a grant from Miles (now Bayer) Canada Inc.

9. Garber GE, Auger P, Chan RMT, et al. A multicenter open comparative study of parenteral cefotaxime and ceftriaxone in the treatment of nosocomial lower respiratory tract infections. Diagn Microbiol Infect Dis 1992;15:85-8.

10. Schentag JJ, Forrest A, Gos TF, et al. Ciprofloxacin eradicates respiratory tract bacteria more rapidly than cephalosporins in patients with nosocomial pneumonia. Drug 1993;45(Suppl):52.

11. Fink MP, Snydman DR, Niederman MS, et al. Treatment of severe pneumonia in hospitalized patients: Results of a multicenter, randomized, double-blind trial comparing intravenous ciprofloxacin with imipenem-cilastatin. Antimicrob Agents Chemother 1994;38:547-57.

12. Mandell LA, Nicolle LE, Ronald AR, et al. A prospective randomized trial of ceftazidime versus cefazolin/tobramycin in the treatment of hospitalized patients with pneumonia. J Antimicrob Chemother 1987;20:95-107.

13. Khan FA, Basir R. Sequential intravenous-oral administration of ciprofloxacin vs ceftazidime in serious bacterial respiratory tract infections. Chest 1989;96:528-37.

14. Trenholme GM, Schmitt BA, Spear J, et al. Randomized trial of intravenous/oral ciprofloxacin versus ceftazidime in the treatment of hospital and nursing home patients with lower respiratory tract infections. Am J Med 1989;87(Suppl 5A):116S-8S.

15. Janknegt R. Drug interactions with quinolones. J Antimicrob Chemother 1990;26(Suppl D):7-29. 


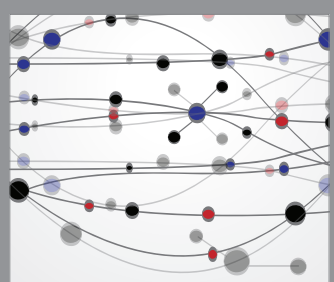

The Scientific World Journal
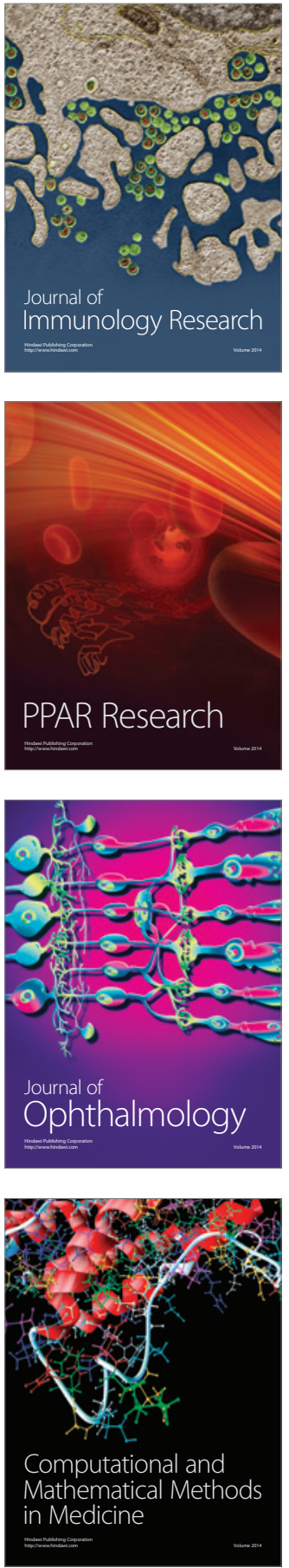

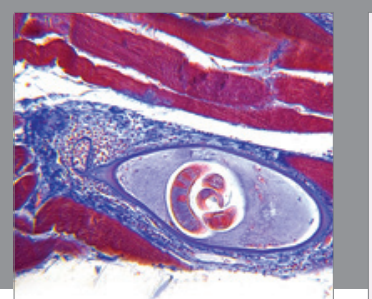

Gastroenterology Research and Practice

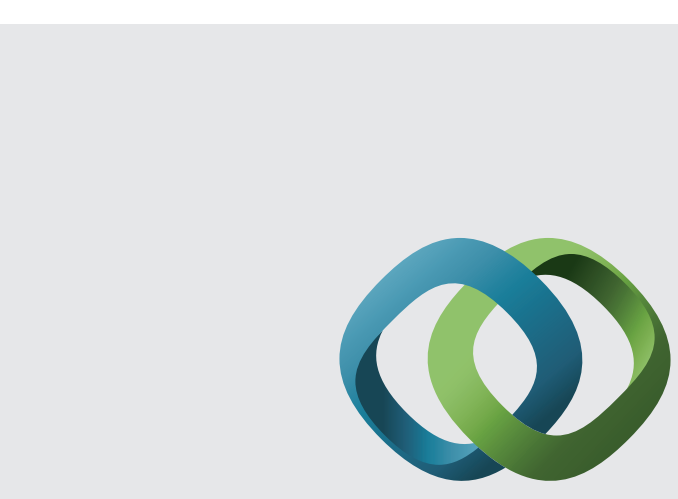

\section{Hindawi}

Submit your manuscripts at

http://www.hindawi.com
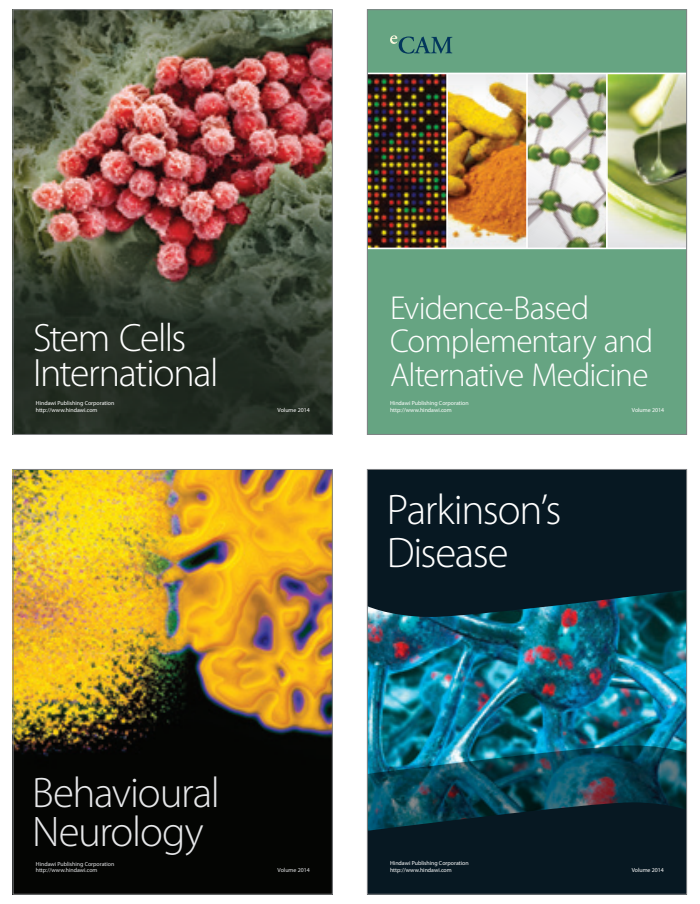
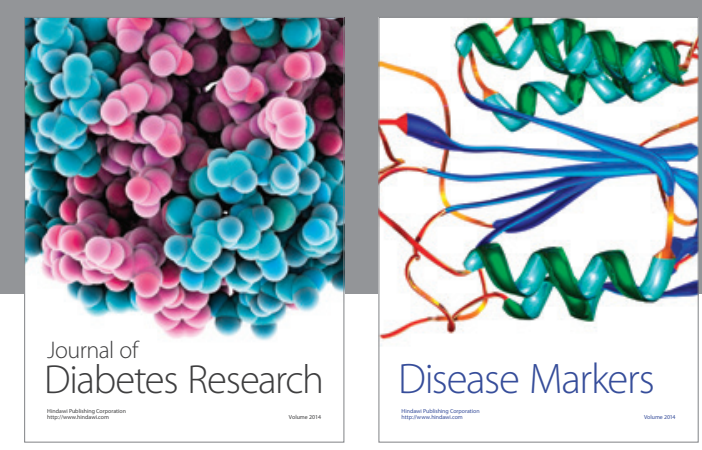

Disease Markers
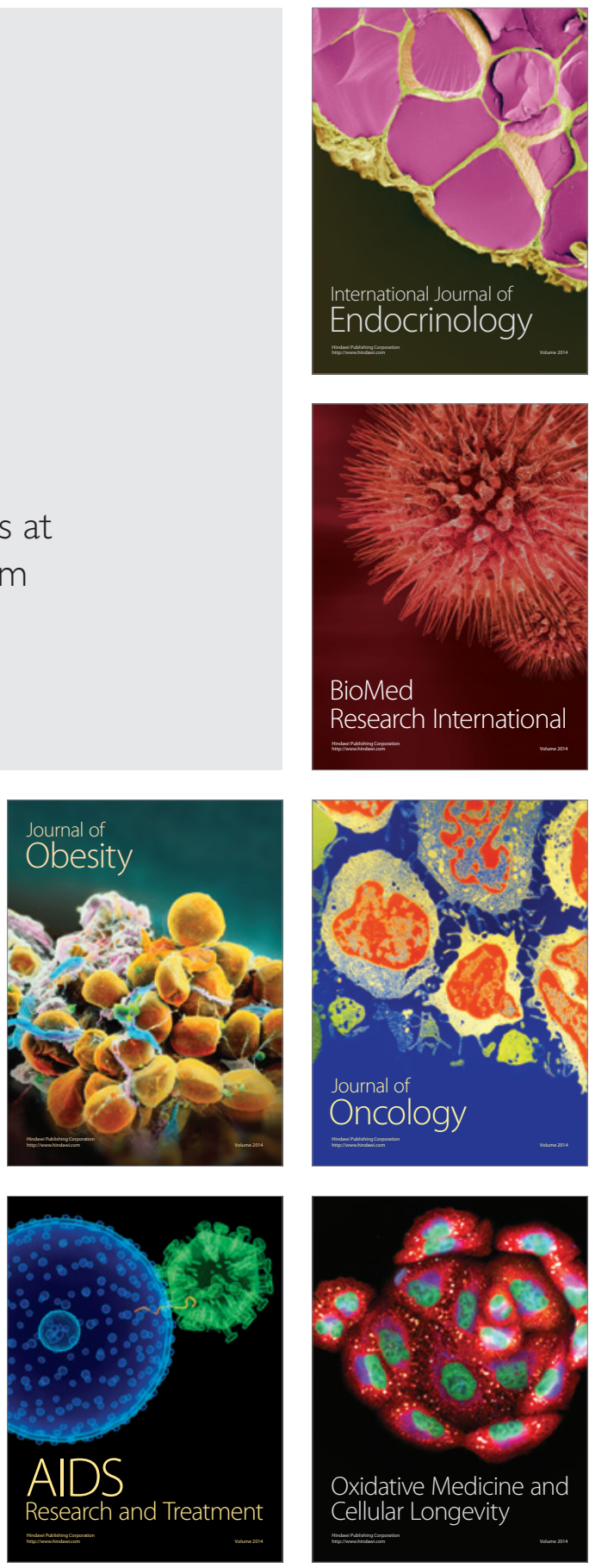